\title{
O TELETRABALHO NA PERCEPÇÃO DOS TELETRABALHADORES
}

\author{
Jouliana Jordan Nohara \\ Doutora em Economia de Empresas pela Fundação Getúlio Vargas - FGV/SP \\ Professor da Universidade Nove de Julho - PMDA/UNINOVE \\ jnohara@uol.com.br
}

\section{Claudia Rosa Acevedo}

Doutora em Administração de Empresas pela Fundação Getúlio Vargas - FGV/SP

Professor aa Universidade Nove de Julho - PMDA/UNINOVE

claudiaraac@uol.com.br

\section{Alice Flora Ribeiro}

Mestre em Administração pela Universidade Nove de Julho - UNINOVE

Professora da Graduação em Administração da Universidade Nove de Julho - UNINOVE

flora@uninove.br

\section{Marcello Muniz da Silva}

Doutorando Engenharia Naval e Oceânica pela Escola Politécnica da Universidade de São Paulo, POLI/USP

Professor da Universidade Nove de Julho - PMDA/UNINOVE

marcelo_muniz@uninove.br

\section{RESUMO}

O objetivo desta investigação foi traçar um quadro da percepção dos teletrabalhadores em relação à qualidade de sua vida profissional. Utilizando-se os dados da pesquisa qualitativa, obtidos por meio de entrevistas individuais em profundidade de uma amostra de vinte teletrabalhadores selecionados por conveniência, conclui-se que o teletrabalho traz bem-estar, melhora na qualidade de vida em relação ao trabalho presencial na empresa. O bem-estar do trabalhador relaciona-se com a sua saúde física e mental e com o impacto positivo desses fatores na eficácia organizacional. A contribuição teórica do artigo consiste na ampliação do conhecimento a respeito dessa forma inovadora de organização do trabalho, que está em franca expansão. Sua contribuição gerencial refere-se a subsídios para a decisão estratégica das organizações sobre a implementação dessa modalidade de trabalho.

Palavras-chave: Formas Inovadoras de Organização do Trabalho, Teletrabalho, Qualidade de Vida No Trabalho. 


\section{INTRODUÇÃO}

Viabilizado pela massificação das tecnologias de informática e telecomunicações (TICs), o teletrabalho é, antes de tudo, uma inovação organizacional que dissolve o espaço e o tempo. O local de trabalho, antes restrito às fronteiras organizacionais, pode ser exercido virtualmente de qualquer ponto do planeta, deixando fluidos os limites geográficos das organizações e demandando ajustes em inúmeros aspectos das práticas administrativas, tais como o planejamento das atividades, formação de equipes de trabalho, distribuição das tarefas, prazos de execução das tarefas, controle da mão-de-obra e relação dos teletrabalhadores com a empresa, a cultura organizacional e os colegas.

No Brasil não há um registro oficial sobre os teletrabalhadores, no entanto, a Sociedade Brasileira de Teletrabalho e Teleatividades (2007) estimou em 3,5 milhões os teletrabalhadores no país em 2003. Apenas entre 2000 e 2001 verificou-se um aumento de $25 \%$ no número de teletrabalhadores no Brasil (Gaspareto Junior, 2002).

A atenção acadêmica acompanha a evolução da prática do teletrabalho. Uma pesquisa na base de dados Ebsco (Business Source Elite) mostra a ausência de artigos acadêmicos sobre o tema nos anos 1970. De janeiro de 1980 até dezembro de 1989 há apenas 21 artigos. Há um aumento substancial dos artigos dedicados ao tema nos anos 1990. De janeiro de 1990 até dezembro de 1999, podemos encontrar 230 artigos na base de dados Ebsco - ou mais de dez vezes o número encontrado nos anos 1980. Na base de dados Scientific Electronic Library Online - SciELO - Brasil, há registro de apenas um artigo sobre o tema, publicado por Costa (2007). Acompanhando a presença de artigos na base de dados Ebsco, podemos deduzir que o tema é relativamente recente, levando em consideração a produção encontrada na SciELO Brasil, o assunto pode ser considerado praticamente ausente, apesar dos milhões de teletrabalhadores no país.

Conforme Brocklehurst (2001) e Dimitrova (2003) a literatura aborda o problema de duas perspectivas. A primeira de ponto de vista da administração relacionada fundamentalmente ao controle e ao perfil, capacidades e características necessárias aos teletrabalhadores e as às vantagens do teletrabalho para as empresas e para a sociedade. A segunda perspectiva aborda a preocupação com a qualidade de vida no trabalho, os custos e os benefícios para o teletrabalhador.

Esta investigação atende a segunda perspectiva. O arcabouço teórico selecionado para compreender o fenômeno em questão foram os conceitos de prazer e sofrimento no trabalho na abordagem de Chanlat (1996), Dejours (1987, 2005, 2007) e Dejours et al. (2007). O objetivo 
desta investigação é analisar as representações sociais de teletrabalhadores sobre o teletrabalho. Mais especificamente, as dimensões investigadas nesta pesquisa foram: flexibilidade, autonomia, isolamento, relação com a vida familiar, estresse e satisfação.

O método empregado na investigação foi o método de análise das representações sociais, que é uma forma de análise hermenêutica norteada por pressupostos metodológicos construtivistas (SPINK, 2003). Jodelet (2001) define as representações sociais como conhecimentos populares e de senso comum que são socialmente produzidos e compartilhados pelos membros de uma comunidade a fim de construir o mundo real no qual eles estão inseridos. Segundo Jovechelovitch (2003), o sujeito constrói a si próprio à medida que elabora sobre o mundo que o constitui. Dessa forma, o entendimento da vida social está atrelado à subjetividade do indivíduo.

Da mesma forma, Magnani (1986) explica que as representações sociais são apreendidas como uma imagem mental do mundo real que é formada pelas experiências e interações dos indivíduos com a realidade que os cerca. Além disso, essa realidade é formada por elementos como a família, os amigos, os vizinhos, o grupo religioso, a categoria profissional e a classe social a que o indivíduo pertence. Para o autor, as representações sociais se manifestam por meio do discurso e das narrativas dos sujeitos. Além disso, quando se investiga as representações sociais de uma coletividade, passa-se a conhecer de que modo esse grupo engendra sua identidade, seus valores, atitudes e comportamentos (Oliveira; Werba, 1998).

Foram realizadas vinte entrevistas em profundidade individuais com teletrabalhadores que foram escolhidos por conveniência para participarem da pesquisa. Além disso, a técnica utilizada para a interpretação das narrativas foi a análise de conteúdo das narrativas.

A contribuição teórica do artigo consiste na expansão do conhecimento a respeito dessa modalidade de trabalho em franca expansão. Sua contribuição gerencial relaciona-se à percepção dos teletrabalhadores a respeito de suas vidas no trabalho e do seu trabalho na vida. Essas informações proporcionam condições para contratação de teletrabalhadores e para a melhora na qualidade de trabalho e de vida dos teletrabalhadores.

\section{TELETRABALHO}

Um dos principais fatores que impedem a avaliação da adoção do teletrabalho é justamente o fato de não haver terminologia clara e estabelecida definindo o que ele é (COSTA, 2003). O Trade Union Congress do Reino Unido escolheu a mais sucinta definição do teletrabalho, que é: "Trabalho à distância facilitado pelas tecnologias de informação e comunicação" (Di Martino, 2001, p. 11, tradução dos autores). 
Teletrabalho é uma forma de organização e/ou de execução de trabalho, com utilização de tecnologia de informação, no contexto de um contrato de trabalho/relacionamento, no qual o trabalho, que também pode ser executado nas dependências do empregador é realizado fora dessas dependências em bases regulares (European Trade Union Confederation, 2002).

A literatura aponta quatro modalidades de teletrabalho: o teletrabalho realizado no domicílio, em telecentros comunitários ou locais, em telecentros satélites e em telecentros móveis. No entanto, o tipo mais conhecido e mais adotado em todo o mundo é o Teletrabalho em casa, devido a sua facilidade de aproveitamento dos recursos previamente existentes do empregado. As empresas procuram este tipo de Teletrabalho, pois podem implantá-lo rapidamente, com baixo investimento e de maneira parcial (Nilles, 1997).

Os centros de teleserviço são sustentados e equipados por empresas diversas, em locais próximos à residência dos empregados, de onde prestam serviços remotamente, por meio de meios eletrônicos e de comunicação. Segundo Nilles (1997), os telecentros comunitários ou locais constituem-se em centros com equipamentos de informática e telecomunicações que ficam próximas às residências e à disposição dos funcionários de várias empresas para executarem suas atividades profissionais.

A adoção de telecentros comunitários reduz o isolamento do convívio profissional do teletrabalhador e mantém a sua rotina de transitar da casa para o escritório, o que pode vir a ser vantajoso para os indivíduos que não conseguem adaptar a sua atividade laboral à sua vida doméstica. Os telecentros satélites são formados por um conjunto de instalações, suficientes e adequadas, como equipamentos de processamento e comunicação, softwares e material de apoio de uma determinada empresa, num local próximo à residência dos funcionários (Nilles, 1997). Já os denominados móveis são na verdade equipamentos específicos que permitem ao funcionário fazer e enviar o seu trabalho em trânsito. Seja por tecnologia de comunicação sem fio ou por acesso a uma linha telefônica (Nilles, 1997). A modalidade examinada no presente artigo é o teletrabalho realizado no domicílio.

As pesquisas sobre teletrabalho encontraram que existem vários aspectos positivos (vantagens), quanto negativos (desvantagens) do teletrabalho. Em relação às vantagens para a sociedade, foram identificadas a redução do tráfego viário e com os gastos do Governo (da sociedade) com infra-estrutura viária; a redução de combustível, da poluição e das pressões nos meios de transporte urbano; a redução de problemas regionais de desemprego; o desenvolvimento regional e inclusão social dos deficientes físicos no mercado de trabalho etc.

Revista de Administração e Inovação, São Paulo, v. 7, n. 2, p. 150-170, abr./jun. 2010 
Além disso, verificou-se que o teletrabalho tem trazido várias vantagens para as empresas: redução de custos indiretos determinada pelos menores custos de infra-estrutura em relação ao trabalho presencial; menores problemas de convivência entre os funcionários; maior produtividade devido ao trabalho por objetivos e a remuneração por resultados; eliminação dos controles de horário; melhora dos prazos de entrega; eliminação do absenteísmo; facilidade de expansão geográfica na busca de talentos; possibilidade de crescimento sem mudanças estruturais; possibilidade de contratação de mão-de-obra mais barata de áreas com baixa oferta de emprego; facilidade de expansão geográfica. Por sua vez, as desvantagens para as empresas identificadas pela literatura especializada são as seguintes: possibilidade de perda de confidencialidade dos dados da empresa; pode haver perda de hierarquias na empresa; conflitos entre os teletrabalhadores e os presenciais; maior dificuldade no controle de evolução do trabalho; maior dificuldade em motivar os teletrabalhadores; maior dificuldade em absorver e se identificar com a cultura da empresa, dificuldade de assegurar a lealdade do teletrabalhador à empresa.

Por outro lado, algumas das vantagens para os teletrabalhadores apresentadas na literatura são: redução dos gastos com locomoção, vestimentas e alimentação fora do trabalho; maior autonomia e mobilidade; menos deslocamentos e redução da fadiga; possibilidade de compatibilizar o trabalho com a vida familiar, resultando em melhora da vida familiar; escolha pessoal do ambiente de trabalho; horário flexível; mais tempo livre; trabalho autônomo e independente; maiores oportunidades de trabalho; adaptação do trabalho à vida e a vida ao trabalho; e melhor qualidade de vida. Por sua vez, verificou-se que entre as desvantagens para os teletrabalhadores estão: a maior insegurança no trabalho por duas razões; a falta de legislação específica no Brasil e a maior possibilidade de demissão em função da falta de contato direto com a empresa. Além disso, há considerações sobre a falta de ambiente de trabalho coletivo no qual o trabalhador pode contar com a experiência, camaradagem e a ajuda dos pares e supervisores, fatos que resultam em menores chances de promoção e de desenvolvimento profissional. Por sua vez, a redução da movimentação pode provocar sedentarismo e refletir negativamente na saúde do teletrabalhador. Mais desvantagens são atribuídas ao isolamento social e às defesas contra o sofrimento enfraquecidas pela falta do entorno social laboral.

\section{FUNDAMENTAÇÃO TEÓRICA}

O artigo está fundamentado na interseção de dois planos de análise: (i) o da dicotomia sofrimento-prazer no trabalho - principal tema na obra de Christophe Dejours e (ii) a Teoria das Representações Sociais (TRS). Para Dejours prazer e sofrimento coexistem no trabalho, contudo

Revista de Administração e Inovação, São Paulo, v. 7, n. 2, p. 151-170, abr./jun. 2010 
há preponderância de um desses elementos que está na origem do bem-estar e a saúde ou do sofrimento e da doença do trabalhador. O prazer se evidencia por meio do reconhecimento, da valorização, da realização e da satisfação no trabalho. Prazer ou sofrimento são identificados pelos sentimentos manifestos e latentes por meio da interpretação do discurso. Aqui entra a TRS, para a qual, o estudo das representações sociais "constitui uma contribuição decisiva para a abordagem da vida mental individual e coletiva" (Jodelet, 2001, p. 22).

\subsection{SOFRIMENTO E PRAZER NO TRABALHO NA ÓTICA DEJOURIANA}

$\mathrm{Na}$ ótica de Dejours, "o trabalho aparece definitivamente como um operador fundamental na própria construção do sujeito [...] ele é também um espaço de construção do sentido e, portanto, de conquista de identidade de continuidade e historicização do sujeito." (DEJOURS et al., 2007, p. 143).

O trabalho, contudo, contém duas condições intrínsecas geradoras de sofrimento: (i) a própria realidade do trabalho ao ser confrontada com os desejos do sujeito e (ii) as relações sociais caracterizadas 'o por relações de desigualdade, de poder e de dominação'.

O sofrimento é definido como uma vivência individual, muitas vezes inconsciente, de experiências dolorosas como medo, angústia e insegurança decorrentes do conflito entre as necessidades de gratificação do binômio corpo-mente e a restrição de satisfazê-las, pelas imposições das situações de trabalho.

A realidade do trabalho, na medida em que compreende a realidade limitada do conteúdo das tarefas se contrapõe aos desejos do sujeito, apresentando-se como geradora de sofrimento. O impacto entre história individual, com desejos, projetos e esperanças e a organização do trabalho que os ignora, resulta em sofrimento, transformada em insatisfação, medo e angústia (Dejours, 1997). Aqui sobressaí a questão de como o sujeito percebe a diferença entre sua realidade psíquica - emocional e cognitiva - e as a prescrições do trabalho?

Sempre sob a forma de fracasso: o real se revela ao sujeito pela sua resistência aos procedimentos, ao saber-fazer, à técnica, ao conhecimento, isto é, pelo fracasso da mestria. O mundo real resiste. Ele confronta o sujeito ao fracasso, de onde surge um sentimento de impotência, até mesmo de irritação, cólera ou ainda de decepção ou de esmorecimento (Dejours, 2004, p. 28).

Quanto às relações sociais no trabalho, Dejours (2004) afirma: 
O trabalho não é apenas uma atividade; ele é, também, uma forma de relação social, o que significa que ele se desdobra em um mundo humano caracterizado por relações de desigualdade, de poder e de dominação. Trabalhar é engajar sua subjetividade num mundo hierarquizado, ordenado e coercitivo, perpassado pela luta para a dominação. [...] O real do trabalho, não é somente o real do mundo objetivo; ele é, também, o real do mundo social (DEJOURS, 2004, p. $31)$.

Esses são os dois eixos determinantes do sofrimento na análise dejouriana. Além dos sofrimentos relacionados com riscos do trabalho, o autor enumera o sofrimento proveniente do temor de não satisfazer as exigências do trabalho, da organização, as imposições de ritmo, de formação, de informação aprendizagem, experiência, nível de instrução, rapidez de aquisição de conhecimentos teóricos e práticos, de adaptação à cultura ou a ideologia da empresa, às exigências do mercado, às relações com os clientes

E há o sofrimento fundamentado no controle ininterrupto gerador de medo de ser vigiado e da ansiedade advinda do risco de ser pego em erro. Medo e ansiedade são os meios para se respeitar os preceitos hierárquicos. Contudo, mesmo que não exista o controle direto o sujeito pode introjetar a prática de controle, tornando-se controlador de si próprio e lidando com o sofrimento decorrente (Dejours, 2007, p. 28).

O imperativo do ajuste entre a subjetividade e a organização do trabalho origina o sofrimento. O próprio ajuste, contudo, demanda a organização a inteligência, a criatividade e a inventividade de cada sujeito no trabalho e a elaboração de defesas individuais e coletivas contra o sofrimento e a modificação do sujeito. A criatividade e o engenho devem ser reconhecidos no espaço de discussão.

O reconhecimento da qualidade do trabalho confere sentido ao esforço, às angustias, às decepções e às dúvidas. O reconhecimento do trabalho, reconduzido pelo sujeito no plano da construção de sua identidade "se traduz afetivamente por um sentimento de alivio, de prazer, às vezes de leveza d'alma ou até de elevação" (DejourS, 2007, p. 34).

O sofrimento não foi em vão e o trabalho se inscreve na dinâmica da realização do ego. O sentimento de reconhecimento, reconhecimento impacta no âmbito das relações sociais como aceitação pelo grupo e/ou pelos pares e ter liberdade para expressar sua individualidade.

Além do reconhecimento, o prazer do trabalho relaciona-se com o fato do trabalho ser escolhido ou organizado livremente pelo sujeito e na adaptação do conteúdo da tarefa às competências reais do trabalhador. De acordo com Dejours (2007):

Revista de Administração e Inovação, São Paulo, v. 7, n. 2, p. 151-170, abr./jun. 2010 
Deixar maior liberdade ao trabalhador para rearranjar seu modo operatório e para encontrar os gestos que são capazes de lhe fornecer prazer, isto é, uma expansão ou uma diminuição de sua carga psíquica de trabalho. Na falta de poder assim liberalizar a organização do trabalho, precisa-se resolver encarar uma reorientação profissional que leve em conta as aptidões do trabalhador, as necessidades de sua economia psicossomática, não de certas aptidões somente, mas de todas, se possível, pois o pleno emprego das aptidões psicomotoras, psicosensoriais e psíquicas parece ser uma condição de prazer no trabalho (DEJOURS, 2007, p. 31-32).

Inseridos na esfera da afetividade humana, o sofrimento e o prazer não se prestam à medição ou avaliações quantitativas, a sua apreensão para a pesquisa se revela pelo discurso. $\mathrm{O}$ autor nota a impossibilidade de se verem e, conseqüentemente, quantificarem o sofrimento e o prazer (Dejours, 2007, p. 29). Assim, a via de acesso à vivência subjetiva e intersubjetiva do trabalho passa pela palavra dos trabalhadores. Fato que determina o método qualitativo de análise e justifica a escolha da teoria das representações sociais.

\subsection{A TEORIA DAS REPRESENTAÇÕES SOCIAIS}

A teoria das representações sociais - TRS ou apenas RS - surgiu em 1961 com o trabalho La Psychanalyse: Son image et son public, de Serge Moscovici, e remete a fenômenos de categorização social, que podem ser objetos de análise. As idéias de Moscovici são tidas como retomada das reflexões presentes no trabalho de Durkheim (1989) - considerado um dos pais da sociologia.

Para Durkheim (1989), a capacidade de aprender hábitos e costumes característicos do grupo social no qual está inserido - processo de aprendizado no meio do grupo - o autor denominou de socialização. A consciência coletiva se forma nesse processo e é composta por tudo aquilo que faz o homem sentir, dever ser e se comportar. Os fatos sociais - criados a partir da maneira como a sociedade percebe a si mesma e ao mundo a seu redor - só podem ser explicados por meio dos efeitos sociais que produzem.

As representações coletivas - conceito cunhado por Durkheim (1989) a fim de distinguir o pensamento social do individual - são apreendidas como categorias fundamentais do entendimento humano. Elas desvendam a maneira do grupo de pensar sobre si mesmo nas suas relações com os objetos que o afetam. Considerando a natureza da sociedade e não a dos indivíduos, pode-se compreender como a sociedade se representa a si própria e ao mundo que a cerca (Minayo, 2003).

Revista de Administração e Inovação, São Paulo, v. 7, n. 2, p. 150-170, abr./jun. 2010 
Com o intuito de compreender as formas de propagação da teoria psicanalítica entre os diversos grupos sociais, Moscovici (1961) retoma o estudo de Durkheim. Para ele, como diria Arruda (2002, p. 134), as representações coletivas apresentavam estabilidade em relação às representações individuais, consistindo em um guarda-chuva sob o qual se encontravam crenças, mitos, imagens, o idioma, o direito, a religião e as tradições.

As representações sociais se construiriam na vida cotidiana. Toda a realidade, reconstituída no sistema cognitivo do indivíduo, integra o seu sistema de valores e, ao reger as relações entre os meios físico e social, não é apenas um reflexo da realidade, mas organizadora da realidade individual. Seus contextos - ideológico, social - dependem do momento histórico no qual o indivíduo como parte de um grupo está inserido - e o do grupo como coletividade de indivíduos.

Como práticas mentais originam-se de categorias sociais do pensamento que se modificam na interação. A representação social opera "uma transformação entre o sujeito e o objeto na medida em que ambos se modificam no processo de elaborar o objeto" (ARRUDA, 2002, p. 137). Segundo Magnani (1986), é similar a uma imagem mental da realidade. O que promove essa imagem, a priori, são as experiências individuais decorrentes da realidade no qual está inserido o ator social.

Representação é algo assim como uma espécie de imagem mental da realidade. Os ingredientes dessa imagem seriam, em primeiro lugar, as experiências individuais decorrentes da realidade social em que o ator está imerso, realidade que se apresenta sob forma de círculos concêntricos: família, a rede de vizinhança, o bairro, categoria profissional, partido, classe social, etc (MAGNANI, 1986, p. 128).

A operacionalização do conceito de representação social (tal como construído por Moscovici), que expressa o consenso da comunidade científica, é dada por Jodelet (2001). Segundo a autora a representação social:

É uma forma de conhecimento, socialmente elaborada e partilhada, com objetivo prático, e que contribui para a construção de uma realidade comum a um conjunto social. Igualmente designada como saber de senso comum ou ainda saber ingênuo, natural, esta forma de conhecimento é diferenciada, entre outras, do conhecimento científico. Entretanto, é tida como objeto de estudo tão legítimo quanto este, devido à sua importância na vida social e à elucidação possibilitadora dos processos cognitivos e das interações sociais (JODELET, 2001, p. 22).

A teoria das representações sociais, segundo Arruda (2002), fomenta um conceito para trabalhar com o pensamento social em sua dinâmica e diversidade. Como afirma Spink (2003), as representações sociais, num papel de conhecimento prático, remetem ao estudo do 
conhecimento do senso comum. Sua elaboração, enquanto formas de conhecimento prático que norteiam as ações do dia-a-dia, surgem na interface de duas forças: a primeira são os conteúdos que circulam na sociedade e a segunda são as forças provenientes da interação social.

A concepção da representação social como representações para a ação, que guiam o comportamento, remodelam e reconstituem os elementos do ambiente em que o comportamento tem lugar e se manifestam em palavras, condutas e sentimentos que se institucionalizam, abrindo espaço para a análise a partir da compreensão dos comportamentos sociais e suas estruturas (Minayo, 2003). As investigações congregam mecanismos e fronteiras na construção das identidades ocupacionais, nacionais, étnicas, políticas etc.

As representações sociais "nos guiam no modo de nomear e definir conjuntamente os diferentes aspectos da realidade diária, no modo de interpretar esses aspectos, tomar decisões..." (Jodelet, 2001, p. 17). Nesse sentido tendem a ocupar uma posição central no campo das Ciências Humanas. Elas emergem num dado contexto social, são elaboradas a partir de quadros de percepção que formam os valores, a ideologia e os sistemas de categorização social partilhados pelos grupos sociais. "Circulam nos discursos, são trazidas pelas palavras e veiculadas em mensagens e imagens mediáticas, cristalizadas em condutas e em organizações materiais e espaciais" (Jodelet, 2001, p. 17), refletindo as relações sociais ao mesmo tempo em que contribuem para a sua formação.

Trata-se de situar o senso comum como teia de significados capaz de criar efetivamente a realidade social (Spink, 1993). A utilização da teoria das representações sociais para a compreensão da percepção dos teletrabalhadores sobre a sua qualidade de vida no trabalho parte da observação de que nessa ótica o indivíduo "pode ser abordado como sujeito genérico — como o grupo no indivíduo - , contanto que tenhamos uma compreensão adequada do contexto social por ele habitado" (Spink, 1993, p. 307).

\section{METODOLOGIA}

A técnica de coleta dos dados utilizada foi a entrevista em profundidade individual. Vinte pessoas que os pesquisadores sabiam que se dedicavam ao teletrabalho foram selecionados por conveniência e as entrevistas, realizadas no segundo semestre de 2008, foram gravadas e transcritas. As perguntas feitas aos entrevistados objetivaram compreender as suas percepções e representações sociais sobre o teletrabalho. Mais especificamente, as dimensões investigadas foram: flexibilidade, autonomia e controle, reconhecimento social de seu trabalho, estresse, isolamento social, a vida no trabalho e o trabalho nas suas vidas, a relação entre o trabalho e a vida familiar e a satisfação.

Revista de Administração e Inovação, São Paulo, v. 7, n. 2, p. 150-170, abr./jun. 2010 
Em relação ao perfil dos entrevistados, verificou-se que dos vinte entrevistados, dez pertencem ao gênero masculino e dez ao gênero feminino. Os depoentes estão na faixa etária de 25 a 47 anos. Todos são habitantes da cidade de São Paulo e cursaram terceiro grau. Entre eles, quatro são solteiros, quatro separados e doze casados. Oito dos inquiridos têm de dois a três filhos. Os separados têm os filhos morando em suas casas. Entre os casados, apenas um reside longe da família temporariamente. O tempo de teletrabalho dos entrevistados varia entre dois e onze anos. Para dez entrevistados o teletrabalho foi sugerido pela empresa e aceito por eles. No entanto, para dois deles essa condição foi imposta pela organização. O resto exerceu essa forma de trabalho por escolha pessoal, aceita pela empresa. Do total dos pesquisados, doze têm equipamento próprio, enquanto que oito usam equipamentos pertencentes à empresa. Todos os entrevistados trabalham em casa e já trabalharam com outros formatos de trabalho anteriormente.

A técnica utilizada para a interpretação das narrativas foi a análise de conteúdo sugerida por Spink (2003) para se captar as representações sociais de um grupo. Com essa técnica buscou-se interpretar o significado e o sentido das falas dos teletrabalhadores. Seguiramse as recomendações de Spink (2003) para se estruturar a interpretação dos discursos. Assim, iniciou-se a interpretação dos discursos com uma leitura flutuante do material, com o objetivo de identificar os elementos que poderiam emergir das narrativas. Nesta fase os pesquisadores ficaram atentos tanto para versões contraditórias, como para os silêncios, as hesitações, lapsos e à estruturação das narrativas.

Em uma etapa subseqüente, o discurso foi categorizado utilizando-se algumas dimensões analíticas da visão dejouriana e de prazer e sofrimento, assim como parte das categorias do conceito de Qualidade de Vida no Trabalho (QVT) (Vasconselos, 2001). O mapeamento das entrevistas, ao lado de algumas categorias e indicadores do modelo QVT, possibilitaram a identificação dos diversos indicadores em cada categoria.

Finalmente, é extremamente importante salientar que as representações sociais captadas foram decorrências da somatória da análise das associações e das idéias presentes nos elementos que constituíram as narrativas. Cabe ressaltar que os resultados da pesquisa estão focados nas percepções do grupo e assinalar o caráter limitado e circunstancial inerente a uma pesquisa exploratória como a apresentada nesse trabalho.

\section{RESULTADOS}

A Figura 1 representa a categorização e os principais indicadores que regem a análise dos resultados da pesquisa:

Revista de Administração e Inovação, São Paulo, v. 7, n. 2, p. 151-170, abr./jun. 2010 


\begin{tabular}{|l|l|}
\hline \multicolumn{1}{|c|}{ CATEGORIAS } & \multicolumn{1}{c|}{ PRINCIPAIS INDICADORES } \\
\hline \multirow{2}{*}{ Ambiente e condições de trabalho } & $>$ ambiente físico do trabalho \\
& $>$ escolha livre dessa forma de trabalho \\
& $>$ flexibilidade: de horário; de organização das tarefas \\
& trabalhador
\end{tabular}

\section{Figura 1:Categorias e principais indicadores}

Fonte: elaborado pelos autores

\subsection{AMBIENTE E CONDIÇÕES DE TRABALHO}

Quanto ao ambiente físico do trabalho foi impossível detectar descontentamento ou reclamações nas narrativas. Praticamente todos os entrevistados enfatizam o fato de trabalhar em casa como fundamental não se atendo descrições relacionadas a problemas com o seu ambiente de trabalho. O local de trabalho parece influir no bom humor dos entrevistados. Fazer do escritório uma extensão da casa, com as preferências e comodidades do lar, proporciona-lhes bem estar. Exceção foi um recém divorciado que precisou trabalhar no hotel no qual foi temporariamente acomodado.

Os sujeitos que exercem o teletrabalho de forma geral estão extremamente satisfeitos por terem eleito - e terem sido escolhidos em função de suas características profissionais e pessoais para - esta forma de trabalho. Mais que isso há orgulho nas narrativas. Como já mencionamos dois dos entrevistados foram obrigados pelas empresas a exercer o teletrabalho. Eles expressam descontentamento, como se pode ver da narrativa de um deles: "Não me sinto a vontade com esse jeito de trabalhar.

Afinal não tive escolha... talvez se tivesse escolha, escolheria ficar no escritório" (informação verbal) ${ }^{1}$.

\footnotetext{
${ }^{1}$ Informação verbal fornecido por um Projetista de nível superior incompleto.
} 
A flexibilidade no horário, no local e na organização do trabalho foi apontada como um dos aspectos mais compensadores do teletrabalho por quase todos os entrevistados. Para eles a flexibilidade permite melhor desempenho e identidade com o trabalho. Verificou-se que os entrevistados percebem como um indicador positivo planejar sua própria agenda. Segundo eles, este foi o motivo fundamental da sua opção por esse formato de trabalho. Eles relatam que a flexibilidade permite que eles ofereçam maior assistência à família, disponham melhor do tempo e conduzam suas atividades do seu jeito.

Outra vantagem comentada pelos entrevistados foi a possibilidade de voltar imediatamente ao escritório quando têm uma boa idéia. Isso não seria possível de imediato se, por exemplo, o sujeito tivesse a idéia em casa, no fim de semana, e só pudesse executá-la ou sugeri-la na segunda-feira. "Claro, se você pode voltar para o seu escritório sempre que tiver um insight, você tem possibilidade de produzir mais do que o colega de escritório que tem hora para trabalhar" (informação verbal) ${ }^{2}$.

A flexibilidade dos horários de expediente evita, na medida do possível, as saídas de casa nas horas de pico do trânsito e a obrigatoriedade de transitar por determinados lugares em horários perigosos. Além disso, permite que atividades antes difíceis de compatibilizar, como esportes e cursos de aperfeiçoamento, por exemplo, possam ser realizadas. "A flexibilidade no tempo é muito importante pra mim... é mais cômodo, mais seguro... eu tinha de ir de madrugada... é perigoso por causa do lugar" (informação verbal) ${ }^{3}$; "Eu moro em Congonhas e trabalhava no Sumaré, isso representava às 7:00 horas da noite um congestionamento de cerca de duas horas todos os dias. Eu tirei esse congestionamento da minha vida, então eu ganhei não só financeiramente como em qualidade de vida" (informação verbal) ${ }^{4}$; "Eu acho que o fato de eu estar em casa trabalhando, me dá essa qualidade de vida... poder cuidar de minha saúde, ir ao médico, nadar, fazer yoga, ou estar em casa, não pegar estresse da rua, do trânsito" (informação verbal $)^{5}$; "Eu queria ter liberdade para poder fazer aula de tênis (...) na hora do almoço, fazer natação" (informação verbal) .

Quanto à flexibilidade na organização das tarefas, os entrevistados relataram que a gerência do próprio ritmo de trabalho exige disciplina. No entanto, alguns disseram terem se tornado mais organizados com o decorrer do tempo e da experiência com o teletrabalho.

\footnotetext{
${ }^{2}$ Informação verbal fornecido por um Projetista de nível superior incompleto.

${ }^{3}$ Informação verbal fornecido por um Gerente.

${ }^{4}$ Informação verbal fornecido por uma Tradutora.

${ }^{5}$ Informação verbal fornecido por uma Pesquisadora.

${ }^{6}$ Informação verbal fornecido por uma Pesquisadora.
} 
Contaram que aprenderam a se organizar tanto na vida pessoal como na profissional. Um aspecto importante deste item são as regras de integração do escritório com a casa, como o espaço reservado somente para o escritório, a separação das atividades profissionais das atividades domésticas e o cumprimento do planejamento pessoal. Um dos depoentes, no entanto, demonstrou dificuldades no planejamento da sua própria rotina de trabalho e no estabelecimento do bom relacionamento com o empregador. As falas a seguir ilustram a flexibilidade na organização do trabalho. "Acho que quando você faz o seu horário, você produz melhor e mais... também posso parar a hora que eu quero" (informação verbal) ${ }^{7}$.

No que tange a adaptação do conteúdo das tarefas às competências reais do trabalhador, não há qualquer menção nos depoimentos sobre falta de adaptação.

\subsection{AUTONOMIA E CONTROLE}

Quanto ao tema de autonomia e controle, os respondentes revelam que não precisam de supervisão de terceiros. Entretanto, admitem que a falta de controle sobre a rotina pode trazerlhes problemas. Além disso, a autonomia é diversas vezes mencionada como um fator positivo por permitir a flexibilidade dos horários de trabalho. Os trechos a seguir ilustram essa impressão.

"Eu faço os meus horários... eu sou meu próprio chefe... posso levar minha filha pro colégio de manhã... ir ao médico, e trabalhar de madrugada que é quando eu sou mais produtivo" (informação verbal) ${ }^{8}$; "Faço meu horário, mas procuro manter uma certa regularidade. Sabe, é aquela coisa... se você não tem um horário as coisas podem descambar tanto para um lado e não trabalhar, como para outro e trabalhar demais” (informação verbal)9; “A coisa é que ninguém pode tirar isso de mim, sabe... se eu quero parar porque tô com dor de barriga, eu paro; se eu quero tomar um banho porque tá muito quente, ... o fato de eu poder fazer as escolhas... não é que nem no escritório que você já estressa só de olhar para cara do chefe..." (informação verbal) ${ }^{10}$.

Há poucas exceções nos relatos nesse indicador: “Ah, o trabalho aumenta... você se compromete bem mais com o Teletrabalho... às vezes as o chefe estressa, porque dependendo do dia o ele fica ligando à toda a hora" (informação verbal) ${ }^{11}$; "O controle começa na hora que eu

\footnotetext{
${ }^{7}$ Informação verbal fornecido por uma Tradutora.

${ }^{8}$ Informação verbal fornecido por um Engenheiro de Vendas.

${ }^{9}$ Informação verbal fornecido por um Gerente de Projeto.

${ }^{10}$ Informação verbal fornecido por um Designer.

${ }^{11}$ Informação verbal fornecido por um Engenheiro de Vendas.
} 
recebo a tarefa. Aí a cada 2 dias eu tenho que mandar um relatório dizendo em que fase do projeto eu estou" (informação verbal) ${ }^{12}$. Em termos gerais, o medo e a ansiedade - meios para se respeitar os preceitos hierárquicos - e o sofrimento fundamentado no controle ininterrupto gerador desses sentimentos negativos, presentes na abordagem dejouriana, estão praticamente ausentes nos depoimentos.

Entretanto, como já mencionado, o sujeito pode introjetar a prática de controle, tornando-se controlador de si próprio e lidando com o sofrimento decorrente e a análise dejouriana assume o sofrimento muitas vezes inconsciente. Alguns relatos proporcionam condições para verificação da apreensão e do medo, como por exemplo: “Tem momentos que dá para ficar apreensivo porque o trabalho tá muito atrasado, só porque eu tive que resolver outros problemas meus" (informação verbal) ${ }^{13}$.

A maior parte dos depoimentos, contudo, permite vislumbrar, as características pessoais dos teletrabalhadores, em função das quais foram eleitos para esse tipo de trabalho. Essas características incluem: capacidade de adaptação, flexibilidade, autodisciplina, senso de responsabilidade, lealdade, autonomia, mais claramente, pessoas capazes de se auto administrar. Substitui-se no teletrabalho a presença física do supervisor, por métodos de monitoramento à distância e pela cobrança por resultados, o que nas palavras de Taskin e Devos (2005), resulta no paradoxo da autonomia controlada (Taskin; Devos, 2005, p. 18).

Como os teletrabalhadores estão privados do ambiente de trabalho com colegas e superiores, as defesas por eles elaboradas são individuais, reais ou imaginárias, como por exemplo: "Se uso menos tempo para a execução de um projeto, não informo a firma imediatamente que eu terminei" (informação verbal) ${ }^{14}$; "Também posso parar a hora que eu quero, que eu sei que não vou produzir tanto e faço outras coisas" (informação verbal) ${ }^{15}$.

\subsection{INTEGRAÇÃO SOCIAL}

O sentimento de isolamento social é produto direto das características essenciais do teletrabalho. Os teletrabalhadores podem se sentir invisíveis para a empresa (Taskin; Devos, 2005). No entanto, nenhum dos entrevistados se referiu a qualquer dificuldade nesse sentido, embora um deles tenha apontado que isso pode se tornar um problema para algumas profissões.

\footnotetext{
${ }^{12}$ Informação verbal fornecido por um Projetista.

${ }^{13}$ Informação verbal fornecido por um Gerente de Projeto.

${ }^{14}$ Informação verbal fornecido por um Web Designer.

${ }^{15}$ Informação verbal fornecido por uma Tradutora.
} 
Já no que diz respeito ao isolamento profissional, para a maioria deles, tal fato revelouse negativo devido aos sentimentos de pertencimento e o compartilhamento de experiências. Eles temem ser excluídos da rede social da empresa, pois se isto ocorrer, seu senso de identidade com a empresa pode esmorecer e fazer com eles não se sintam comprometidos com a corporação nem com as atividades que desempenham.

Os trechos dos depoimentos a seguir transmitem essas idéias: "O isolamento é maior... essa é outra coisa que é ruim, porque acaba te afastando, fica muito distante... o comprometimento pessoal depende da qualidade da inserção na empresa" (informação verbal) ${ }^{16}$; "Eu acredito que se a pessoa não se policiar, começa a se transformar numa pessoa anti-social (...) o distanciamento acaba fazendo que isso vire uma rotina (...), não é o meu caso, mas eu tenho colegas assim" (informação verbal) ${ }^{17}$.

Para outros, no entanto, o afastamento dos colegas de trabalho e do chefe é bem vindo, seja pela característica da profissão ou pela própria personalidade do entrevistado. A comunicação com os colegas de trabalho para todos é facilitada pelas tecnologias de telecomunicação e, segundo argumenta a maioria dos entrevistados, flui melhor dessa maneira, pois as relações tornam-se mais objetivas e proveitosas.

\subsection{O ESPAÇO DO TRABALHO NA VIDA E O DA VIDA NO TRABALHO}

Observa-se, nos relatos, que o trabalho em casa propiciou maior tranqüilidade nos assuntos domésticos, como cuidar e acompanhar os filhos ou partilhar mais tempo com o cônjuge. A interação com a família aumentou e mostrou-se prazerosa. Ficou evidente a satisfação pela tranqüilidade de estar próximo dos filhos e por poder acompanhá-los nas suas atividades diárias. Essa evidência é mais contundente no caso do universo feminino da pesquisa. O fato de poder estar perto da família tornou-se um ponto positivo para os entrevistados, mesmo tendo que recorrer à imposição de uma disciplina para os membros da casa.

Por outro lado, observa-se que muitos dos entrevistados confessaram desorganização no dimensionamento de sua jornada de trabalho e do período de lazer no início da passagem para o formato de teletrabalho. Alguns deles tiveram que adaptar gradualmente o ambiente doméstico à sua nova condição profissional.

\footnotetext{
${ }^{16}$ Informação verbal fornecido por um Engenheiro de Vendas.

${ }^{17}$ Informação verbal fornecido por um Pesquisador.
} 
Outros entrevistados revelaram, entretanto, ainda fazer confusão entre a vida familiar e a profissional. Relataram dar mais atenção ao labor, pois trabalhando por tarefa, à medida que precisam ou querem ganhar mais, aumentam a própria carga de trabalho. No entanto, admitem a necessidade de se organizarem melhor. Em dois dos casos houve ocorrência de conflitos familiares. Um deles teve problemas com a família culminando na separação do casal. A novidade e a falta de organização acabaram provocando uma dedicação excessiva à recente atividade profissional e fez com que o entrevistado negligenciasse sua vida pessoal. Em conseqüência da separação, teve que instalar seu escritório provisoriamente num hotel, o que trouxe transtornos para ele e a empresa para a qual trabalhava. O outro enfrentou problemas de adaptação com a mãe, pelo fato dela interromper constantemente seu trabalho. A solução foi sair da casa dos pais. Alguns trechos dos depoimentos a seguir caracterizam estes problemas: “O contato familiar é uma grande vantagem porque mesmo estando isolada no meu escritório eu estou dentro de casa e em qualquer emergência meus filhos têm acesso direto a mim" (informação vebral) ${ }^{18}$; "Essa idéia de que eu estou em casa, mas não estou disponível (para a família), é um trabalho que exige certa perseverança e uma certa insistência... No começo foi difícil delimitar as fronteiras... Hoje em dia meus filhos já vêem que se eu estou no escritório, eu estou trabalhando" (informação verbal) 19; "Você perde a noção do tempo porque você está em casa; trabalha muito mais, principalmente na minha área em que a quantidade de trabalho significa aumento de rendimento. Isso gera alguns problemas... não consegui impor alguns padrões de conduta dentro de casa" (informação vebral) ${ }^{20}$.

A colaboração da família é fundamental para o equilíbrio do indivíduo. Se não houver apoio da família, e vice-versa, o indivíduo acaba tendo problemas.

Embora os teletrabalhadores que moram com membros da família reconheçam que o tempo com a família aumenta, revelam também que o tempo para a família fica na mesma proporção. Nesse caso, as estratégias são mais limitadas e de difícil implementação, e a dificuldade de lidar com elas impõe grande custo emocional (Costa, 2003).

Já em relação aos amigos, parentes ou outras pessoas da comunidade, os entrevistados destacaram que tais indivíduos freqüentemente tinham a percepção de que o entrevistado estava em momento de lazer quando na verdade estava trabalhando. Alguns depoentes relataram

\footnotetext{
${ }^{18}$ Informação verbal fornecido por um Jornalista.

${ }^{19}$ Informação verbal fornecido por uma Tradutora.

${ }^{20}$ Informação verbal fornecido por um Web Designer.
} 
situações em que amigos ou parentes interferiram no andamento de suas atividades ao insistirem em se comunicar com eles durante as horas de trabalho. A fala a seguir exemplifica este tipo de situação: "Foi engraçado... meu vizinho já é aposentado. Ele achava que como eu estava em casa, eu não trabalhava. Minha mulher saia para trabalhar, aí ele vinha me convidar para jogar damas... perturbava, foi dificil o cara entender ${ }^{, 21}$.

\subsection{RECONHECIMENTO}

O reconhecimento da qualidade do trabalho confere sentido ao esforço, às angustias, às decepções e as dúvidas e reconduzido pelo sujeito no plano da construção de sua identidade "se traduz afetivamente por um sentimento de alivio, de prazer" (DEJOURS, 2007).

Há poços indícios nos relatos dos entrevistados sobre o reconhecimento. Existem mais queixas e reclamações de incompreensão dos colegas que exercem trabalho nas instalações físicas da empresa. Os colegas pensando que os teletrabalhadores não estão trabalhando de fato. Queixas pela falta de compreensão, dos familiares, dos amigos e dos vizinhos que, muitas vezes, não entendem as exigências desse tipo de trabalho e seu impacto sobre os teletrabalhadores.

A falta de relatos sobre o reconhecimento do trabalho não diminui a satisfação que os teletrabalhadores expressam sentir em relação ao seu trabalho.

\section{COMENTÁRIOS FINAIS}

Os relatos apresentam formas singulares de percepção ao lado de um discurso comum ao grupo social. Diversas experiências de vida e formas de socialização explicam as singularidades dos depoimentos. O núcleo central, que capta o cerne da representação social da vida profissional dos teletrabalhadores, está concentrado em satisfação e orgulho de serem teletrabalhadores.

Com exceção a dois dos entrevistados, todas as pessoas inquiridas asseguraram que estão felizes com o teletrabalho. Verificou-se que esse aspecto está relacionado com itens como autonomia, flexibilidade de horários e a vida com a família. A razão alegada por eles, advém da constatação de uma melhor qualidade de vida, maior tranqüilidade e bem estar, decorrência da possibilidade de trabalharem no ambiente familiar.

\footnotetext{
${ }^{21}$ Informação verbal fornecido por um Auxiliar Executivo.
} 
Nenhum dos respondentes fez considerações sobre a satisfação que a remuneração por produção lhes oferece. Destacaram, com maior ênfase, a liberdade de ação, o conforto e a oportunidade de empreender suas próprias soluções. Por outro lado, os entrevistados para os quais o teletrabalho foi imposto, demonstraram sentimentos de frustração.

A redução do estresse e o maior equilíbrio psicológico revelam-se nos discursos dos depoentes como reflexo da inserção do trabalho em ambiente confortável, da autonomia e da flexibilidade no trabalho. Para a maior parte, o teletrabalho traz bem-estar e maior qualidade de vida.

No entanto, nem todos se sentem assim. Segundo alguns dos pesquisados, a razão do estresse ainda vem da chefia. São teletrabalhadores vigiados por ligações telefônicas de seus superiores cobrando resultados imediatos. Por outro lado, a redução no tempo e nos custos de deslocações entre casa e trabalho são fatores que contribuem para a redução do estresse. A tranqüilidade de não precisar enfrentar o deslocamento diário para o trabalho significa vantagem inquestionável para eles. Além de não haver perda de tempo e nem cansaço físico e mental, com as horas gastas no trânsito.

A limitação do número de respondentes, a amostra composta apenas por trabalhadores altamente qualificados, o fato da pesquisa ser restrita apenas à cidade de São Paulo e a um grupo que exerce suas atividades exclusivamente em domicílio não permitem generalização dos resultados.

Muitos autores (Brocklehurst, 2001; Costa, 2003; Dimitrova, 2003) têm afirmado que os estudos sobre o teletrabalho apresentam um caráter promocional, esse estudo, infelizmente, não escapa dessa descrição. O fato, acreditamos, se deve à introjeção dos valores do discurso gerencial corrente pelos teletrabalhadores da amostra, que por seu lado são escolhidos em função das suas características pessoais, atitudes e aptidões para o teletrabalho. Ou seja, são eleitos exatamente por terem as características imprescindíveis para serem teletrabalhadores.

\section{REFERÊNCIAS}

Arruda, A. Teoria das representações sociais e teorias de gênero. Caderno de Pesquisas, São Paulo, n. 117, p. 127-147, nov. 2002.

Brocklehurst, M. Power, identity and new technology homework: implications for 'new forms' of organizing. Organization Studies, London, v. 22, n. 3, p. 445-466, 2001.

Revista de Administração e Inovação, São Paulo, v. 7, n. 2, p. 151-170, abr./jun. 2010 
Chanlat, J.F. O indivíduo na organização. Três volumes. São Paulo: Atlas, 1996.

Costa, I. S. A. Poder/saber e subjetividade na construção do sentido do teletrabalho. 2003. Tese (Doutorado) - Escola Brasileira de Administração Pública e de Empresas, Fundação Getulio Vargas, Rio de Janeiro, 2003.

Costa, I.S. A. Teletrabalho: subjugação e construção de subjetividades. Revista de Administração Pública, Rio de Janeiro, v. 41, n. 1, p. 105-124, jan./fev. 2007.

Dejours, C. A banalização da injustiça social. 7. ed. Rio de Janeiro: FGV, 2007.

Dejours, C. A Loucura do trabalho: estudo de psicopatologia do trabalho. 2. ed. São Paulo: Cortez, 1987.

Dejours, C. O fator humano. 5. ed. Rio de Janeiro: FGV, 2005.

Dejours, C. et al. Psicodinâmica do trabalho: contribuições da escola Dejouriana à análise da relação prazer, sofrimento e trabalho. São Paulo: Atlas, 2007.

Di Martino, V. The high road to teleworking. Geneva: International Labour Organization, 2001.

Dimitrova, D. Controlling teleworkers: supervision and flexibility revisited. New Technology, Work \& Employment, Oxford, v. 18, n. 3, p. 181-195, Nov. 2003.

Durkheim, E. As formas elementares de vida religiosa. São Paulo: Paulinas, 1989.

European Trade Union Confederation. Framework agreement on telework. Brussels: ETUC, 2002.

Gaspareto Junior, R. et al. A sociedade da informação no Brasil: presente e perspectivas. São Paulo: Takano, 2002.

Jodelet, D. (Org). As representações sociais. Rio de Janeiro: UERJ, 2001.

Jovchelovitch, S. Vivendo a vida com os outros: intersubjetividade, espaço público e representações sociais. In: GUARESCHI, P. A.; JOVCHELOVITCH, S. (Org). Textos em representações sociais. 8. ed. Petrópolis: Vozes, 2003. p. 63-85.

Magnani, J. Discurso e representação ou de como os balomas de Kiriwina podem reencarnar-se nas atuais pesquisas. In: CARDOSO, Rute. L. (Org.). A aventura antropológica. Rio de Janeiro: Paz e Terra, 1986. p. 127-140.

Moscovici, S. La Psychanalyse: Son image et son public. Paris: PUF, 1961.

Moscovici, S. Representações sociais: investigações em psicologia social. Rio de Janeiro, Vozes, 2003.

Minayo, M. O conceito de representações sociais dentro da sociologia clássica. In: Guareschi, P. A.; Jovchelovitch, S. (Org). Textos em representações sociais. 8. ed. Petrópolis: Vozes, 2003. p. 89-111. 
Nilles, J.M. Fazendo do teletrabalho uma realidade: um guia para telegerentes e teletrabalhadores. Tradução Eduardo Pereira e Ferreira. São Paulo: Futura, 1997.

Oliveira, F.O.; Werba, G. C. Representações sociais. In: STREY, M. N. et al. Psicologia social contemporânea. Petrópolis: Vozes, 1998. p. 104-117.

Sociedade Brasileira de Teletrabalho e Teleatividades. Pesquisa geral no site. Disponível em: <http://www.sobratt.org.br/>. Aceso em: 08 dez. 2007.

Spink, M. O conceito de representação social na abordagem psicossocial. Cadernos de Saúde Pública, Rio de Janeiro, v. 9, n. 3, p 300-308, jul./set. 1993.

Spink, P. Pesquisa de campo em psicologia social: uma perspectiva pós-construcionista. Psicologia e Sociedade, Florianópolis, v. 15, n. 2, p. 18-42, jul./dez. 2003.

Taskin, L.; Devos, V. Paradoxes from the individualization of human resource management: the case of telework. Journal of Business Ethics, Dordrecht, v. 62, n. 1, p. 13-24, Nov. 2005.

Vasconselos, A. F. Qualidade de vida no trabalho: origem, evolução e perspectivas. Caderno de Pesquisas em Administração, São Paulo, v. 8, n. 1, p. 23-35, jan./mar. 2001.

\title{
TELECOMMUTING WORKER'S PERCEPTION OF TELEWORK
}

\begin{abstract}
The objective of this research was analyze the perception of teleworkers in relation to the quality of their professional life. Using the data from the qualitative research obtained through in depth individual interviews of a sample of twenty random teleworkers selected, it was concluded that teleworking brings welfare benefits to its workers which improved their quality of life. The worker's welfare is related to his/her physical and mental health that brings a positive impact to factors of organizational effectiveness. The theoretical contribution of the article is to broaden knowledge about this booming, innovative way of organizing work. Its management contribution refers to strategic decisions by the companies about the implementation of telecommuting.
\end{abstract}

Keywords: Innovative Forms Of Work Organization, Telework, Quality Of Work Life.

Data do recebimento do artigo: 28/10/2009

Data do aceite de publicação: 12/03/2009

Revista de Administração e Inovação, São Paulo, v. 7, n. 2, p. 151-170, abr./jun. 2010 